\section{Actinic lichen nitidus}

\author{
Travis W. Blalock, Swati Kannan, \\ Loretta S. Davis \\ Medical College of Georgia, Division \\ of Dermatology, Augusta, GA, USA
}

\begin{abstract}
We present the case of a 29-year-old black female with an initial clinical and histopathologic diagnosis of actinic lichen nitidus. Three years later, she presented with scattered hyperpigmented macules with oval pink/violaceous plaques bilaterally on her forearms and on her neck, clinically consistent with actinic lichen planus. She was treated with topical steroids at each visit, with subsequent resolution of her lesions. In this report, we discuss the spectrum of actinic lichenoid dermatoses and of disease that presents even in the same patient.
\end{abstract}

\section{Case Report}

A 29-year-old black woman presented with a complaint of a photo-distributed dermatitis that had erupted each spring or summer for many years. An initial physical examination revealed several dark brown patches bilaterally on her forearms with interspersed 1- to 2-mm monomorphic lichenoid papules. A punch biopsy specimen of her left forearm revealed a lichenoid infiltrate, compact orthokeratosis, and absence of hypergranulosis (Figures 1 and 2 ). Three years later, she presented with scattered hyperpigmented macules with oval pink/violaceous plaques on both forearms (Figure 3), as well as a 3-cm plaque on her lower neck posteriorly.

\section{Microscopic findings and clinical course}

The histopathologic examination of the punch biopsy specimen revealed a lichenoid lymphohistiocytic infiltrate and abundant melanophages, expanding the papillary dermis, mimicking the classic "ball-in-claw" histology of lichen nitidus. The epidermis displayed slight hyperplasia, compact orthokeratosis with abundant Civatte bodies, and a few foci of parakeratosis. No wedge-shaped hypergranulosis was noted. These findings are characteristic of actinic lichen nitidus (ALN). The patient was educated regarding sun protection and prescribed a class I topical corticosteroid to use intermittently for flare-ups, which improved this photosensitive eruption.

\section{Discussion}

The first description of ALN was reported in India in 1978 by Bedi, ${ }^{1}$ who described 25 patients with hypopigmented pinpoint papules in sun-exposed areas and termed this photosensitive eruption "summertime actinic lichenoid eruption" (SALE). In 1981, Isaacson et al. reported a similar case of an AfricanAmerican female with pinpoint papules and annular plaques. Both authors described the histopathology as similar to lichen nitidus. ${ }^{2,3}$

The report by Isaacson et al. expanded SALE to include other types of lichenoid eruptions such as hyperpigmented plaques, pinpoint papules, and lichen planus (LP)-like papules, considering them part of a spectrum of actinic lichen planus (ALP), but preferring the term SALE. ${ }^{2-4}$ In a later report of nine patients with ALN, Hussein argued against using the broader term SALE. He reported the co-occurrance of ALP and ALN in two of the nine patients, which would appear to be the case in our patient with a diagnosis of ALN and who later presented with oval violaceous plaques on her neck and forearms, a clinical picture more consistent with ALP. ALN and ALP present mostly in children and young adults with darkly pigmented skin, following significant sun exposure. ALN, a rare photo-induced eruption, shares the same histological features as lichen nitidus

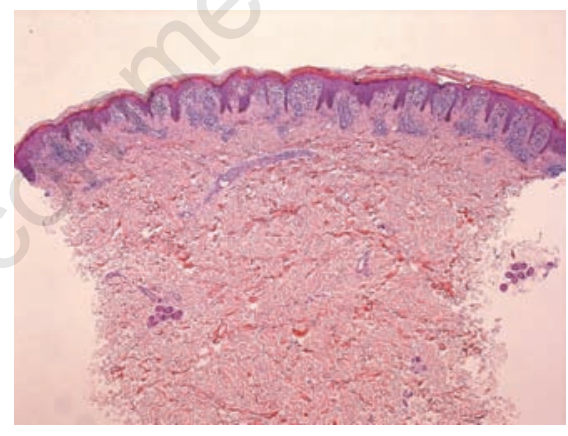

Figure 1. Low power magnification of lesion biopsied on initial presentation.

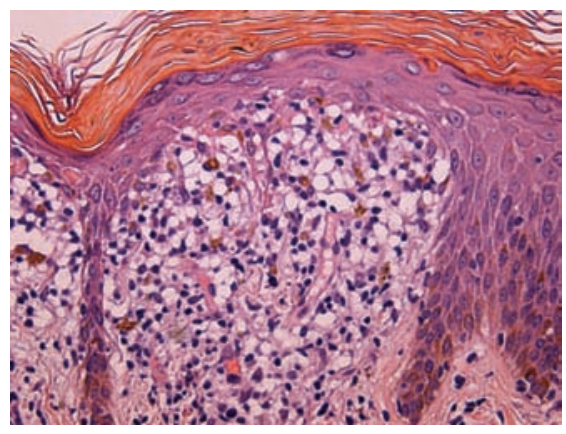

Figure 2. High power magnification of lesion biopsied on initial presentation.
Correspondence: Travis W. Blalock, Medical College of Georgia, Division of Dermatology, 1004 Chafee Ave., Augusta, GA 30904, USA.

E-mail: twblalo@msn.com

Key words: lichenoid dermatitis; actinic lichen nitidus, actinic lichen planus.

Contributions: TWB, LSD, SK, study concept and design; TWB, SK, acquisition of data; TWB, LSD, SK, analysis and interpretation of data; TWB, SK, drafting of the manuscript; TWB, LSD, critical revision of the manuscript for important intellectual content; TWB, LSD, SK, administrative, technical, or material support; LSD, study supervision; TWB, LSD, SK, had full access to all of the data in the study and take responsibility for the integrity of the data and the accuracy of the data analysis

Received for publication: 1 July 2010.

Revision received: 7 July 2010

Accepted for publication: 7 July 2010.

This work is licensed under a Creative Commons Attribution 3.0 License (by-nc 3.0).

@C Copyright T.W. Blalock et al., 2010

Licensee PAGEPress, Italy

Dermatology Reports 2010; 2:e10

doi:10.4081/dr.2010.e10

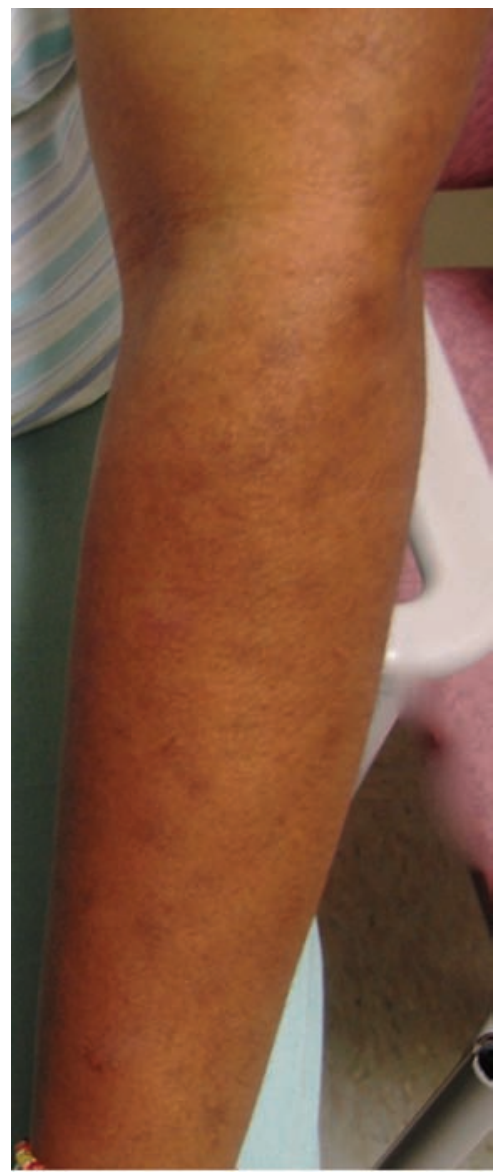

Figure 3. Clinical presentation on followup visit. 
including parakeratosis, absent granular layer, basal cell liquefaction, and a "ball-in-claw" arrangement of lymphocytic infiltrate. ${ }^{2,45}$ In addition, ALN usually presents with pinpoint lichenoid papules, restricted to sun-exposed areas. ${ }^{4}$ In contrast, typical ALP lesions are oval or annular plaques with hypopigmented, palpable borders, and hyperpigmented centers that appear depressed or atrophic. ${ }^{6-9}$ The histopathology of ALP includes hyperkeratosis, wedge-shaped hypergranulosis, and necrotic keratinocytes with a band-like lymphocytic infiltrate, similar to classic LP. ${ }^{6,8}$ Based on differences both clinically and histopathologically, ALN and ALP are distinct entities. The term ALN should describe miliary papules with lichen nitidus-like histopathology, and ALP should refer to annular lesions with LP-like histological features. Patients with both types of lesions can be considered to have related diagnoses or diagnoses that lie on a continuum, which is comparable to the co-occurrence of classic LP and lichen nitidus. ${ }^{2}$

\section{References}

1. Bedi TR. Summertime actinic lichenoid eruption. Dermatologica 1978;157:115-25.

2. Hussain K. Summertime actinic lichenoid eruption, a distinct entity, should be termed actinic lichen nitidus. Arch Dermatol 1998;134:1302-3.

3. Isaacson D, Turner ML, Elgart ML. Summertime actinic lichenoid eruption (lichen planus actinicus). J Am Acad Dermatol 1981;4:404-11.

4. Summey BT, Cusack CA. Actinic lichen nitidus. Cutis 2008;81:266-8.

5. Rallis E, Verros C, Moussatou V, et al. Generalized purpuric lichen nitidus. Report of a case and review of the literature. Dermatol Online J 2007;13:5.

6. Kim GH, Mikkilineni R. Lichen planus actinicus. Dermatol Online J 2007;13:13.

7. MacFarlane AW. A case of actinic lichen planus. Clin Exp Dermatol 1989;14:65-8.

8. McKee PH, Calonje JE, Granter S. Lichenoid and interface dermatoses. In: Pathology of the skin with clinical correlations. 3rd edn, Vol 1. 2005; Ch 6, p 217-60.

9. Zanca A, Zanca A. Lichen Planus actinicus. Int J Dermatol 1978;17:506-8. 